\title{
UNDERSTANDING THE HOLOBIONT: THE INTERDEPENDENCE OF PLANTS AND THEIR MICROBIOME
}

Carmen Sanchez-Cañizares*, Beatriz Jorrín*, Philip S. Poole, Andrzej Tkacz*

${ }^{*}$ Contributed equally to this work

Department of Plant Sciences, University of Oxford, South Parks Road, OX1 3RB, Oxford, UK

Corresponding author: Andrzej Tkacz (andrzej.tkacz@plants.ox.ac.uk)

\begin{abstract}
The holobiont is composed by the plant and its microbiome. In a similar way to ecological systems of higher organisms, the holobiont shows interdependent and complex dynamics [1,2]. While plants originate from seeds, the microbiome has a multitude of sources. The assemblage of these communities depends on the interaction between the emerging seedling and its surrounding environment, with soil being the main source. These microbial communities are controlled by the plant through different strategies, such as the specific profile of root exudates and its immune system. Despite this control, the microbiome is still able to adapt and thrive. The molecular knowledge behind these interactions and microbial "-omic" technologies are developing to the point of enabling holobiont engineering. For a long time microorganisms were in the background of plant biology but new multidisciplinary approaches have led to an appreciation of the importance of the holobiont, where plants and microbes are interdependent.
\end{abstract}

\section{Introduction}

Plants do not live alone. Indeed, a vast diversity of microorganisms colonise all their organs, making up their microbiome. Since the first break-trough paper describing the Arabidopsis thaliana microbiome [3] numerous articles have appeared illustrating the microbiome diversity of different model plants such as Brachypodium distachyon, Medicago truncatula, Lotus japonicus or Marchantia polymorpha [4-7], and crops like rice, maize, sugarcane, barley, soybean and cowpea [8-13]. Current plant microbiome studies aim to investigate its structure under a variety of conditions, for example, host plant species, soil type and temporal and spatial differences $[4,14,15]$. 


\section{How is the microbiome assembled?}

Even though microorganisms are millions of times smaller than animal and plants, some of the ecological relationships are conserved and hence can be compared [16]. For example, as in the case of higher organisms, microbiome diversity correlates with the size of the habitat. This was observed in natural enclosed environments like treehole pools, where microbial genetic diversity increased with the volume sampled [17]. Moreover, the state of a microbial community is the result of its succession in time. As in the case of plants colonising new areas with fast-growing and resistance species, a microbiome starts with autotrophic cyanobacteria, whose diversity rises sharply at the beginning and remains stable over time. The presence of cyanobacteria is linked to a high organic carbon and nitrogen content in soils, paving the way for the colonisation of higher organisms [18]. Disturbed environments support microorganisms with a higher response to nutrient inputs, and they evolve into more specialised, but metabolically slower assemblages, as concluded from recording of rRNA operon numbers and heterogeneity [19].

Another important similarity between higher organisms and microbial communities is the existence of keystone species. As starfish in rock ponds [20] or wolves reintroduced in Yellowstone National Park [21], a keystone species may not be dominant in numbers but play a critical role maintaining community diversity. A microbial example comes from the plant phyllosphere, where microbial communities evolved together with a plant-parasitic Albugo oomycete. When the pathogen was removed, there was a reduction in the diversity of the ecosystem [22]. It implies that we need to carefully consider adding or removing even single but important community members, as these modifications may have consequences for the whole ecosystem and hence for the plant host which we are trying to protect.

The plant holobiont is a good example in nature showing how a good communication and an interactive dialogue between two partners leads to a better performance [23]. This relationship usually starts in the rhizosphere as, in most cases, the initial reservoir of microbial diversity is the soil. As the compounds that attract and select preferred microorganisms are present in root exudates and mucilage, microorganisms would migrate from the root to different plant organs above ground (Figure 1). This partnership between host and its associated community has to be studied throughout time, as there are many factors affecting these microbial assemblies. The controversial co-evolution between the host and its microbiota leads sometimes to adaptive gene 
loss, known as the "black queen hypothesis" [24,25]. For example Blattabacterium, termite gut-associated bacteria have become specialized by losing genes involved in vitamin and amino acid biosynthesis [26].

\section{Where does the plant microbiota come from?}

As aforementioned, most microbiota members are horizontally acquired from the surrounding environment where soil is the main reservoir of a plant's microbiome $[3,10,27,28]$, whereas the air only exerts a minute contribution to the organs above ground [29]. As the plant microbiota is mostly determined by soil communities, understanding the factors determining microbial diversity and richness of soil are of paramount importance to studying plant microbiome assemblage. A global factor here is soil pH [30-34]. Soils of low pH harbour homogeneous communities dominated by Acidobacteria, while those with higher $\mathrm{pH}$ show a highly diverse microbial population $[14,35]$. In turn, the soil is also influenced by root exudates, which are rich in organic carbon compounds, leading to the assembly of the plant microbiome below ground. Indeed, the amount of organic carbon determines the presence of typical copiotrophic microorganisms that grow well in rich organic environments, such as Proteobacteria, Bacteroidetes or Actinobacteria [36,37].

The influence exerted by the root on the microbiome varies across the different physical compartments in which the soil-root system is divided: bulk soil (where the soil microbiome is not influenced by the plant root), rhizosphere (the soil influenced by the root), rhizoplane (microbiota attached to the plant root) and the endosphere (the microbiota inside the root) $[3,38]$. Microbiome diversity seems to be inversely proportional to the influence of the root, being highest in bulk soil and lowest in the endosphere, mostly due to a high degree of plant selection [38-40]. The drivers of this plant recruitment are not yet defined. Which approach should we use to uncover selection by the plant? The use of plants mutated in genes involved in plant-microbe interactions and screening their affected microbiome is now uncovering the biology behind this selection. For instance, Lebeis et al. [41] showed the importance of plant defence hormones in $A$. thaliana. The absence of pad4, a gene activated by salicylic acid, prevents the enrichment of Actinobacteria, which was previously observed in the root endosphere of $A$. thaliana [38]. In the case of wheat, the presence of jasmonic acid changes the structure of microbial communities of the root endosphere by enriching in phytopathogen-supressing taxa [42]. Microbiome structural changes were 
also used as a proxy to uncover a link between phosphate acquisition pathway and immune system. A set of $A$. thaliana mutant plants in phosphate accumulation pathways showed a distinctive assembly of communities, which were modulated by PHR1. As the master regulator of the phosphate starvation response and also required for the jasmonic acid response, nutrient acquisition was prioritised over defence [43].

As plants strongly select their specific microbiome, they reduce their overall microbial diversity, paving the way to pathogen emergence [44,45]. Crop plant monocultures are examples of continuous plant selection over vast areas and long time scales $[18,46,47]$.

Although the majority of the plant microbiome diversity is acquired during plant life from its surrounding environment, it seems that part of it could also be inherited from the seed [48] (Figure 1). Seed-associated microorganisms play a role in early stages of plant development, affecting germination and seedling survival [49]. Soil microorganisms appear later and have to compete against the already established microbiota. The microorganisms selected in the rhizosphere will move to the rest of the plant and colonise different organs [50,51]. The main organ to which these communities migrate is the leaf. Phyllosphere communities have been directly associated with outbreaks of different human illnesses due to the presence of enteric pathogens [52]. This highlights the importance of knowing the origin of the different microbial assemblages in each plant organ, in order to prevent or minimise pathogen outbreaks. If we know the microbial reservoir (soil, air or seed-borne), we can predict the colonisation pattern of pathogenic microorganisms. In the case of phyllosphere microbiome studies, the use of plastic plants in field experiments has been described as an appropriate control to capture air-borne communities. This work claimed that only a small subset of the phyllosphere community is selected by the plant, as there is equal colonisation of the leaves of both the real tomato and its inert partner [29]. The origin of these communities is unknown, however it has been suggested that low-growing plants acquire their phyllosphere microbiome mostly from the soil [28].

\section{How do plants fine-tune their microbiome?}

Despite the environmental origin of different microbial communities, the plant itself is obviously a key player in the holobiont, actively influencing the composition and function of its microbiota. As mentioned previously, factors such as the plant species, the developmental stage and the plant compartment define different microbial 
assemblages, but also important are the plant immune system, its metabolism and ability to secrete nutrients. Microbial communities respond and adapt themselves to these factors. For example, the loss of nitrogen-fixing symbiosis in L. japonicus alters the structure of the community assemblages in the root and rhizosphere compartments [6]. GC-MS on root exudates from gnobiotically-grown $A$. thaliana plants has shown that the levels of sugars and sugar alcohols decreased through plant development, whereas the levels of amino acids and phenolics increased over time [53]. Root exudates, composed of sugars, organic acids and amino acids, strongly affect the composition of microbial plant communities, with Actinobacteria and Proteobacteria being the primary consumers of these compounds [54]. In the microbiota of barley roots, genes involved in sugar uptake were enriched compared to their presence in soil samples [11]. A mutation of an $A B C$ transporter involved in root exudation caused changes in the fungal and bacterial rhizosphere communities of $A$. thaliana [55]. However, in the absence of a plant, the addition of organic acids, rather than sugars, stimulates bacterial richness and diversity [56]. Nutrient acquisition is a strong driver of microbial assemblage. Just as in the rhizosphere, nutrient availability also drives the phyllosphere community. The leaf cuticle acts as diffusion barrier; plant mutants with a disturbed cuticle affect the composition and relative abundance of their associated microbiota [57]. Whereas the abundance of Rhodococcus decreases because they feed on cuticle components, Variovorax, a genus with broad spectrum metabolic capabilities, increases its presence [58].

Microbial surface structures, mostly based on carbohydrates, are also essential for the establishment of successful interactions between the plant and its microbial partners. A rhamnose-deficient lipopolysaccharide mutant of Rhizobium sp. IRBG74 lose the ability to nodulate Sesbania cannabina and show significant reduction in colonisation of rice roots [59]. These microbial surface structures are usually perceived by plant LysM receptors, a family of proteins involved in the first recognition steps upon microbial infection and part of the plant immune system. LysM receptors detect structurally similar molecules, for example, nodulation (Nod) factors produced by rhizobial symbionts; chitin, the surface polymer in fungi, or bacterial peptidoglycan surface polymers [60]. On their surfaces bacteria display a variety of glycans (the major component of bacterial biofilms) that help them to colonise different niches and evade the plant immune system. A key finding, opening new perspectives on carbohydrate signalling and perception, has been the discovery of the transmembrane LysM receptor kinase, EPR3 [61]. First described in L. japonicus, this receptor is able to directly bind exopolysaccharide (EPS), a major bacterial surface polymer composed of sugar 
residues. EPR3 distinguishes between compatible and incompatible EPS and is thus involved in signal perception leading to a successful interaction. Not only that, but EPR3 expression is inducible and dependent on host perception of bacterial Nod factors, mediating the plant-bacterial compatibility and leading to rhizobial access into legume roots in a tightly-controlled symbiosis.

Microbial pathogens strategically acquire metabolites from their hosts during infection, either as energy sources or signalling molecules [62]. However, the plant has developed strategies to interfere and prevent metabolite loss to pathogens. In $A$. thaliana, the sugar transporter 13 (STP13) is phosphorylated by BAK1 (BRASSINOSTEROID INSENSITIVE 1-associated receptor kinase 1) a co-receptor of flagellin, one of the main bacterial structural components that triggers the immune response upon detection [63]. STP13 phosphorylation enhances plant monosaccharide uptake activity from their own apoplast to outcompete phytopathogenic bacteria, suppressing effector delivery and thereby reducing their virulence. Regulation of metabolite uptake upon recognition of microorganisms might constitute a plant defence strategy to limit pathogen proliferation. Adapted microbes coexist in the phyllosphere. These bacterial communities are limited by carbon availability, thus access to carbon compounds on leaves is a major determinant of epiphytic colonisation [64]. A cultureindependent analysis of the microbiota associated with leaves of soybean, clover, and A. thaliana plants using a metaproteogenomic approach showed similar community profiles [65]. The alphaproteobacterial genera Methylobacterium and Sphingomonas were predominantly found. Survival of Methylobacterium was, to a large extent, related to its ability to use methanol as a source of carbon and energy. Sphingomonas had a different strategy to thrive in the phyllosphere based on an active carbohydrate uptake, reflected by a high expression of TonB-dependent receptors, outer membrane proteins involved in this uptake. Thus, through the metabolic profile, the plant is able to define its microbial partners.

\section{Microbiome research breaks into the field of plant engineering}

In the field of plant engineering, microbiome studies are starting to be taken into account. For plants with a disrupted metabolic pathway, this will not only affect its physiology, but also its associated microbiota. A good example is the reduction of lignin levels in forest trees in order to improve the commercial viability of wood. CinnamoylCoA reductase ( $\mathrm{CCR})$ is a central enzyme in the lignin biosynthetic pathway, but when it is silenced, an accumulation of various extractable phenolic compounds occurs in the 
xylem. Field-grown CCR-down-regulated poplar trees substantially influence the microbiome of the plant endosphere. Therefore, a small genetic variation affecting a plant metabolic pathway can generate changes in the community structures and their metabolic capacities [66]. Another major challenge in biotechnology is the transfer of biological nitrogen fixation to cereal crops. Inoculation of maize and wheat with a strain of Pseudomonas protegens able to excrete ammonia and engineered to fix nitrogen, largely improved their nitrogen content and biomass accumulation $[67,68]$. Despite the potential of this strain, in order to release and expand the use of nitrogen-fixing inoculants to diverse soils, the effect on the indigenous microbial communities needs to be evaluated.

While pathogenic and symbiotic interactions are known to induce changes in gene transcription related to plant defence and development, little is known about the molecular mechanisms underlying the phytostimulation of Plant Growth-Promoting Rhizobacteria (PGPRs) [69]. A transcriptomic approach looking for the genes responsible for a favoured interaction on PGPR-inoculated rice plants found a total of 7,384 genes significantly up- or down-regulated upon Azospirillum inoculation ( $16 \%$ of total rice genes). Most of the differentially expressed genes were involved in primary metabolism, transport, regulation of transcription and protein fate [70]. Microorganisms colonising plant tissues try to modulate plant defences to allow their establishment. Rice roots inoculated with the endophyte Herbaspirillum seropedicae showed a decreased expression of genes involved in defence [71]. A transcriptome approach showed that the "crack-entry" symbiont Bradyrhizobium sp. Lb8 induces genes involved in oxidation-reduction, metabolism, hormone biosynthesis and plant defence systems in the root of cultivated peanut (Arachis hypogaea L.). In the case of nitrogenfixing bacteria, defence responses are also induced at the first stages of interaction, but these endosymbionts are able to down-regulate defence-like genes in order to allow their entrance into the root cortex of legume plants and induce nodule formation $[72,73]$.

Defining a model microbial community to increase plant productivity is in the scientific spotlight. The rhizosphere microbiome and root exudates of $B$. distachyon has been established as a model rhizosphere for cereal species [5]. The $B$. distachyon rhizosphere microbiota profiles are similar to those reported for wheat rhizosphere [74], but different from those of $A$. thaliana $[3,38]$. This suggests that microbial communities are influenced by differences in the root system, exudates and mucilage production between monocotyledons and eudicots [5]. Understanding how microbial communities 
assemble is moving the field towards the use of synthetic communities to enhance crop production. The introduction of the endophyte Paraburkholderia phytofirmans PsJN, a powerful plant growth promoter [75], to the flowers of parent plants of various crops (maize, wheat, soybean and pepper) has proven to be an effective strategy for its transmission into progeny seed, thus promoting plant development [50].

\section{Future perspectives and applications}

Initial microbiome studies have been based on a descriptive approach of the different communities present in various plant hosts or conditions. The next step will be to look for functional characteristics and explain how specific communities are influencing the plant. For example, which part of the soil microbiome is linked to the flowering time and biomass in plants? An easy approach would be to record plant growth and its associated microbiome in different conditions, correcting for plant physiology heterogeneity and microbiome stochasticity. A more powerful approach is to enrich the microbiome over a multi-seasonal selection experiment, looking for a desired trait [76]. In A. thaliana, after 10 successive generations, a different microbial community was selected in early and late flowering plants (low and high inflorescence biomass, respectively), both in terms of phylogeny and function. The microbiomes responsible for these traits were transplanted to other closely-related plant species and they reproduced the same effect [76]. These transplants were successful even when using only the cultivable part of the microbiome. However if the viability was affected by freezing the samples, these traits were lost due to a reduction in the community structure [77]. In general, the higher the diversity of the microbial community, the greater the plant biomass that can be obtained. This is possibly due to resource allocation and enhanced evolution, allowing the microbiome to develop desirable functions [78].

However, we are still far from fully understanding microbiome dynamics. A microbiome is usually more efficient in its native state, when all the microorganisms are present, than when only a selected part - albeit highly specialised - is involved. For example, cultivable microorganisms selected for their oil-degrading properties were less able to fulfil their purpose than the native soil microbiome [79]. The functional stability of the microbiome was addressed further by analysing pathogen invasion. A pathogenic strain of Esherichia coli colonised soil better when a poor microbial community was present, compared to a more complex soil microbiome. A strong negative correlation was observed between $E$. coli colonisation and the microbial soil diversity, both in a 
dilution-to-extinction experiment from the original soil microbiome and a synthetic community approach [80]. A similar colonisation effect happened with soil opportunists overtaking the nutrient and diversity-poor rhizosphere of $A$. thaliana plants [4]. Both studies indicate that colonisation of newcomers is strongest in disturbed systems, where resource recycling is lowered due to the absence of certain community members.

Combined "-omics" technologies are leading to a better understanding of the community dynamics. Emerging pipelines for processing large number of samples and improved data analysis allow microbiome studies to be performed in less than 48 hours [81]. Combining automation with network analysis will revolutionise microbial ecology. Network analysis is used to identify microbial taxa that support diversity, but also identify specific taxa that show either a direct negative correlation with a known pathogen, or an indirect correlation due to a positive interaction with pathogen antagonist [82]. Hence, the observation that some microbial taxa are more abundant in the rhizosphere of infected plants does not necessary mean that they have a direct influence. A good example is the enrichment of bacterial taxa feeding on nutrients leaching from Rhizoctonia infected plant roots. Bacterial abundance is an indirect response due to the presence of the pathogen and their potential biocontrol would be of limited value [83]. The approach of assembling synthetic communities will need to incorporate community ecology concepts. These synthetic communities, usually based on biocontrol and biofertilizer species, should be supplemented with both accessory species to obtain a robust diversity and keystone species to maintain the microbiome functional stability (Figure 2). The last crucial step is the ability to culture, store and share microbial strains. A keystone study has proved that, with current technologies, a collection of 400 isolates from roots and leaves of $A$. thaliana can be fully genomically characterized and used to assembly synthetic communities mimicking the initial microbiota structure [84]. These approaches would enable mimicking the plant microbiome in order to engineering the holobiont itself.

\section{Concluding remarks}

Even though the plant has always been considered the main character in plant-microbe interactions, current research projects are highlighting the importance of its associated microbiome. Cutting-edge technologies have led to massive progress in plant microbiology, which is now re-defining our understanding of the coexistence and 
communication between plants and microbes. The field is moving from the initial description of the actors starring in this play in nature, to the full storyline.

Acknowledgements

This work was supported by the Biotechnology and Biological Sciences Research Council [grant numbers BB/N003608/1, BB/K006134/1, BB/N013387/1].

1. Vandenkoornhuyse P, Quaiser A, Duhamel M, Le Van A, Dufresne A: The importance of the microbiome of the plant holobiont. New Phytologist 2015, 206:1196-1206.

2. Hacquard S, Schadt CW: Towards a holistic understanding of the beneficial interactions across the Populus microbiome. New Phytol 2015, 205:1424-1430.

3. Lundberg DS, Lebeis SL, Paredes SH, Yourstone S, Gehring J, Malfatti S, Tremblay J, Engelbrektson A, Kunin V, del Rio TG, et al.: Defining the core Arabidopsis thaliana root microbiome. Nature 2012, 488:86-+.

4. Tkacz A, Cheema J, Chandra G, Grant A, Poole PS: Stability and succession of the rhizosphere microbiota depends upon plant type and soil composition. ISME Journal 2015.

5. Kawasaki A, Donn S, Ryan PR, Mathesius U, Devilla R, Jones A, Watt M: Microbiome and Exudates of the Root and Rhizosphere of Brachypodium distachyon, a Model for Wheat. PLOS ONE 2016, 11:e0164533.

6. Zgadzaj R, Garrido-Oter R, Jensen DB, Koprivova A, Schulze-Lefert P, Radutoiu S: Root nodule symbiosis in Lotus japonicus drives the establishment of distinctive rhizosphere, root, and nodule bacterial communities. Proceedings of the National Academy of Sciences of the United States of America 2016, 113:E7996-E8005.

7. Alcaraz LD, Peimbert M, Dorantes-Acosta AE, Bowman JL, Arteaga-Vazquez MA: Marchantia liverworts as a proxy to plants basal microbiomes. bioRxiv 2017.

8. Edwards J, Johnson C, Santos-Medellín C, Lurie E, Podishetty NK, Bhatnagar S, Eisen JA, Sundaresan V: Structure, variation, and assembly of the root-associated microbiomes of rice. Proceedings of the National Academy of Sciences 2015, 112:E911-E920.

9. Peiffer JA, Spor A, Koren O, Jin Z, Tringe SG, Dangl JL, Buckler ES, Ley RE: Diversity and heritability of the maize rhizosphere microbiome under field conditions. Proc Natl Acad Sci U S A 2013, 110:6548-6553.

10. de Souza RSC, Okura VK, Armanhi JSL, Jorrín B, Lozano N, da Silva MJ, González-Guerrero M, de Araújo LM, Verza NC, Bagheri HC, et al.: Unlocking the bacterial and fungal communities assemblages of sugarcane microbiome. Scientific Reports 2016, 6:28774.

11. Bulgarelli D, Garrido-Oter R, Munch PC, Weiman A, Droge J, Pan Y, McHardy AC, Schulze-Lefert $P$ : Structure and function of the bacterial 
root microbiota in wild and domesticated barley. Cell Host Microbe 2015, 17:392-403.

12. Sugiyama $A$, Ueda $Y$, Zushi $T$, Takase $H$, Yazaki $K$ : Changes in the Bacterial Community of Soybean Rhizospheres during Growth in the Field. PLOS ONE 2014, 9:e100709.

13. Leite J, Fischer D, Rouws LFM, Fernandes-Júnior PI, Hofmann A, Kublik S, Schloter M, Xavier GR, Radl V: Cowpea Nodules Harbor Non-rhizobial Bacterial Communities that Are Shaped by Soil Type Rather than Plant Genotype. Frontiers in Plant Science 2017, 7:2064.

14. Griffiths RI, Thomson BC, James P, Bell T, Bailey M, Whiteley AS: The bacterial biogeography of British soils. Environ Microbiol 2011, 13:1642-1654.

15. Armstrong A, Valverde A, Ramond J-B, Makhalanyane TP, Jansson JK, Hopkins DW, Aspray TJ, Seely M, Trindade MI, Cowan DA: Temporal dynamics of hot desert microbial communities reveal structural and functional responses to water input. Scientific Reports 2016, 6:34434.

16. Fierer N, Lennon JT: The generation and maintenance of diversity in microbial communities. American Journal of Botany 2011, 98:439-448.

17. Bell T, Ager D, Song J-I, Newman JA, Thompson IP, Lilley AK, van der Gast CJ: Larger Islands House More Bacterial Taxa. Science 2005, 308:1884-1884.

18. Liu J, Kong W, Zhang G, Khan A, Guo G, Zhu C, Wei X, Kang S, MorganKiss RM: Diversity and succession of autotrophic microbial community in high-elevation soils along deglaciation chronosequence. FEMS Microbiol Ecol 2016, 92.

19. Nemergut DR, Knelman JE, Ferrenberg S, Bilinski T, Melbourne B, Jiang L, Violle C, Darcy JL, Prest T, Schmidt SK, et al:: Decreases in average bacterial community rRNA operon copy number during succession. Isme $\mathrm{j}$ 2016, 10:1147-1156.

20. Paine RT: Food Web Complexity and Species Diversity. The American Naturalist 1966, 100:65-75.

21. Smith DW, Bangs EE: Reintroduction of Wolves to Yellowstone National Park: History, Values and Ecosystem Restoration. In Reintroduction of Top-Order Predators. Edited by: Wiley-Blackwell; 2009:92-125.

**22. Agler MT, Ruhe J, Kroll S, Morhenn C, Kim S-T, Weigel D, Kemen EM: Microbial Hub Taxa Link Host and Abiotic Factors to Plant Microbiome Variation. PLoS Biol 2016, 14:e1002352.

A network analysis based study showing importance of "hub-taxa" in structuring inter-kingdom plant phyllosphere microbial community

23. Gordon J, Knowlton N, Relman D, Rohwer F, Youle M: Superorganisms and Holobionts. Microbe Magazine 2013.

24. Mas A, Jamshidi S, Lagadeuc $Y$, Eveillard D, Vandenkoornhuyse $P$ : Beyond the Black Queen Hypothesis. ISME J 2016, 10:2085-2091.

25. Morris JJ, Lenski RE, Zinser ER: The Black Queen Hypothesis: evolution of dependencies through adaptive gene loss. MBio 2012, 3.

26. Sabree ZL, Huang CY, Arakawa G, Tokuda G, Lo N, Watanabe H, Moran NA: Genome Shrinkage and Loss of Nutrient-Providing Potential in the Obligate Symbiont of the Primitive Termite Mastotermes darwiniensis. Applied and Environmental Microbiology 2012, 78:204210. 
27. Bulgarelli D, Schlaeppi K, Spaepen S, Ver Loren van Themaat E, SchulzeLefert P: Structure and functions of the bacterial microbiota of plants. Annu Rev Plant Biol 2013, 64:807-838.

28. Wagner MR, Lundberg DS, del Rio TG, Tringe SG, Dangl JL, Mitchell-Olds $\mathrm{T}$ : Host genotype and age shape the leaf and root microbiomes of a wild perennial plant. Nature Communications 2016, 7:12151.

**29. Ottesen AR, Gorham S, Reed E, Newell MJ, Ramachandran P, Canida T, Allard $M$, Evans $P$, Brown E, White JR: Using a Control to Better Understand Phyllosphere Microbiota. PLOS ONE 2016, 11:e0163482.

The use of a better control in the phyllosphere microbiome studies allow to show the low selection effect by the leaf.

30. Fierer N, Jackson RB: The diversity and biogeography of soil bacterial communities. Proceedings of the National Academy of Sciences of the United States of America 2006, 103:626-631.

31. Lauber $C L$, Hamady $M$, Knight $R$, Fierer $N$ : Pyrosequencing-Based Assessment of Soil pH as a Predictor of Soil Bacterial Community Structure at the Continental Scale. Applied and Environmental Microbiology 2009, 75:5111-5120.

32. Rousk J, Baath E, Brookes PC, Lauber CL, Lozupone C, Caporaso JG, Knight $\mathrm{R}$, Fierer $\mathrm{N}$ : Soil bacterial and fungal communities across a pH gradient in an arable soil. ISME J 2010, 4:1340-1351.

33. Ridl J, Kolar M, Strejcek M, Strnad H, Stursa P, Paces J, Macek T, Uhlik O: Plants Rather than Mineral Fertilization Shape Microbial Community Structure and Functional Potential in Legacy Contaminated Soil. Frontiers in Microbiology 2016, 7.

34. Wu Y, Zeng J, Zhu Q, Zhang Z, Lin X: pH is the primary determinant of the bacterial community structure in agricultural soils impacted by polycyclic aromatic hydrocarbon pollution. Scientific Reports 2017, 7:40093.

35. Mukherjee S, Juottonen H, Siivonen P, Lloret Quesada C, Tuomi P, Pulkkinen $\mathrm{P}$, Yrjala K: Spatial patterns of microbial diversity and activity in an aged creosote-contaminated site. ISME J 2014, 8:21312142.

36. Fierer N, Bradford MA, Jackson RB: Toward an ecological classification of soil bacteria Ecology 2007, 88:1354-1364.

37. Prober SM, Leff JW, Bates ST, Borer ET, Firn J, Harpole WS, Lind EM, Seabloom EW, Adler PB, Bakker JD, et al.: Plant diversity predicts beta but not alpha diversity of soil microbes across grasslands worldwide. Ecology Letters 2015, 18:85-95.

38. Bulgarelli D, Rott M, Schlaeppi K, Ver Loren van Themaat E, Ahmadinejad N, Assenza F, Rauf P, Huettel B, Reinhardt R, Schmelzer E, et al.: Revealing structure and assembly cues for Arabidopsis rootinhabiting bacterial microbiota. Nature 2012, 488:91-95.

39. Zarraonaindia I, Owens SM, Weisenhorn P, West K, Hampton-Marcell J, Lax S, Bokulich NA, Mills DA, Martin G, Taghavi S, et al.: The Soil Microbiome Influences Grapevine-Associated Microbiota. mBio 2015, 6.

40. Hartman K, van der Heijden MGA, Roussely-Provent V, Walser J-C, Schlaeppi K: Deciphering composition and function of the root microbiome of a legume plant. Microbiome 2017, 5:2. 
**41. Lebeis SL, Paredes SH, Lundberg DS, Breakfield N, Gehring J, McDonald M, Malfatti S, Glavina del Rio T, Jones CD, Tringe SG, et al.: Salicylic acid modulates colonization of the root microbiome by specific bacterial taxa. Science 2015, 349:860-864.

How the use of plant mutants is helping to decipher the role of certain molecules in the plant-microbe interaction.

42. Liu H, Carvalhais LC, Schenk PM, Dennis PG: Effects of jasmonic acid signalling on the wheat microbiome differ between body sites. Scientific Reports 2017, 7:41766.

43. Castrillo G, Teixeira PJPL, Paredes SH, Law TF, de Lorenzo L, Feltcher ME, Finkel OM, Breakfield NW, Mieczkowski P, Jones CD, et al.: Root microbiota drive direct integration of phosphate stress and immunity. Nature 2017, 543:513-518.

44. Niu J, Rang Z, Zhang C, Chen W, Tian F, Yin H, Dai L: The succession pattern of soil microbial communities and its relationship with tobacco bacterial wilt. BMC Microbiology 2016, 16:233.

45. Zhu Y, Chen H, Fan J, Wang Y, Li Y, Chen J, Fan J, Yang S, Hu L, Leung $\mathrm{H}$, et al:: Genetic diversity and disease control in rice. Nature 2000, 406:718-722.

46. Xiong W, Li Z, Liu H, Xue C, Zhang R, Wu H, Li R, Shen Q: The Effect of Long-Term Continuous Cropping of Black Pepper on Soil Bacterial Communities as Determined by 454 Pyrosequencing. PLOS ONE 2015, 10:e0136946.

47. Hartmann M, Frey B, Mayer J, Mader P, Widmer F: Distinct soil microbial diversity under long-term organic and conventional farming. ISME J 2015, 9:1177-1194.

48. Pitzschke A: Developmental Peculiarities and Seed-Borne Endophytes in Quinoa: Omnipresent, Robust Bacilli Contribute to Plant Fitness. Frontiers in Microbiology 2016, 7.

49. Truyens S, Weyens N, Cuypers A, Vangronsveld J: Bacterial seed endophytes: genera, vertical transmission and interaction with plants. Environmental Microbiology Reports 2015, 7:40-50.

50. Mitter B, Pfaffenbichler N, Sessitsch A: Plant-microbe partnerships in 2020. Microbial Biotechnology 2016, 9:635-640.

51. Hardoim PR, van Overbeek LS, Berg G, Pirttilä AM, Compant S, Campisano A, Döring M, Sessitsch A: The Hidden World within Plants: Ecological and Evolutionary Considerations for Defining Functioning of Microbial Endophytes. Microbiology and molecular biology reviews : MMBR 2015, 79:293-320.

52. Brandl MT: Fitness of human enteric pathogens on plants and implications for food safety. Annu Rev Phytopathol 2006, 44:367-392.

53. Chaparro JM, Badri DV, Vivanco JM: Rhizosphere microbiome assemblage is affected by plant development. ISME Journal 2013.

54. Vandenkoornhuyse $P$, Mahé $S$, Ineson $P$, Staddon $P$, Ostle N, Cliquet J-B, Francez A-J, Fitter $\mathrm{AH}$, Young JPW: Active root-inhabiting microbes identified by rapid incorporation of plant-derived carbon into RNA. Proceedings of the National Academy of Sciences 2007, 104:1697016975.

55. Badri DV, Quintana N, El Kassis EG, Kim HK, Choi YH, Sugiyama A, Verpoorte R, Martinoia E, Manter DK, Vivanco JM: An ABC transporter 
mutation alters root exudation of phytochemicals that provoke an overhaul of natural soil microbiota. Plant Physiol 2009, 151:20062017.

56. Shi S, Richardson AE, O'Callaghan M, DeAngelis KM, Jones EE, Stewart A, Firestone MK, Condron LM: Effects of selected root exudate components on soil bacterial communities. FEMS Microbiol Ecol 2011, 77:600-610.

57. Reisberg EE, Hildebrandt $U$, Riederer $M$, Hentschel $U$ : Distinct Phyllosphere Bacterial Communities on Arabidopsis Wax Mutant Leaves. PLOS ONE 2013, 8:e78613.

58. Bodenhausen N, Bortfeld-Miller M, Ackermann M, Vorholt JA: A Synthetic Community Approach Reveals Plant Genotypes Affecting the Phyllosphere Microbiota. PLOS Genetics 2014, 10:e1004283.

59. Mitra S, Mukherjee A, Wiley-Kalil A, Das S, Owen H, Reddy PM, Ané J-M, James EK, Gyaneshwar P: A rhamnose-deficient lipopolysaccharide mutant of Rhizobium sp. IRBG74 is defective in root colonization and beneficial interactions with its flooding-tolerant hosts Sesbania cannabina and wetland rice. Journal of Experimental Botany 2016.

60. Oldroyd GE: Speak, friend, and enter: signalling systems that promote beneficial symbiotic associations in plants. Nat Rev Microbiol 2013, 11:252-263.

61. Kawaharada Y, Kelly S, Nielsen MW, Hjuler CT, Gysel K, Muszynski A, Carlson RW, Thygesen MB, Sandal N, Asmussen MH, et al.: Receptormediated exopolysaccharide perception controls bacterial infection. Nature 2015, 523:308-312.

62. Rico A, Preston GM: Pseudomonas syringae pv. tomato DC3000 Uses Constitutive and Apoplast-Induced Nutrient Assimilation Pathways to Catabolize Nutrients That Are Abundant in the Tomato Apoplast. Molecular Plant-Microbe Interactions 2008, 21:269-282.

**63. Yamada K, Saijo Y, Nakagami H, Takano Y: Regulation of sugar transporter activity for antibacterial defense in Arabidopsis. Science 2016, 354:1427-1430.

A key finding showing competition for sugar as a plant defense strategy against microbial infection, preventing sugar loss to pathogens by transcriptional and posttranscriptional regulation of a sugar transporter.

64. Lindow SE, Brandl MT: Microbiology of the Phyllosphere. Applied and Environmental Microbiology 2003, 69:1875-1883.

65. Delmotte N, Knief C, Chaffron S, Innerebner G, Roschitzki B, Schlapbach R, von Mering $C$, Vorholt JA: Community proteogenomics reveals insights into the physiology of phyllosphere bacteria. Proceedings of the National Academy of Sciences 2009, 106:16428-16433.

**66. Beckers B, Op De Beeck M, Weyens N, Van Acker R, Van Montagu M, Boerjan W, Vangronsveld J: Lignin engineering in field-grown poplar trees affects the endosphere bacterial microbiome. Proc Natl Acad Sci U S A 2016, 113:2312-2317.

The importance of evaluating and understanding the full consequences of engineering a plant metabolic pathway on its associated microbial community. 
67. Setten L, Soto G, Mozzicafreddo M, Fox AR, Lisi C, Cuccioloni M, Angeletti $M$, Pagano E, Díaz-Paleo A, Ayub ND: Engineering Pseudomonas protegens Pf-5 for Nitrogen Fixation and its Application to Improve Plant Growth under Nitrogen-Deficient Conditions. PLOS ONE 2013, 8:e63666.

68. Fox AR, Soto G, Valverde C, Russo D, Lagares A, Zorreguieta Á, Alleva K, Pascuan C, Frare R, Mercado-Blanco J, et al.: Major cereal crops benefit from biological nitrogen fixation when inoculated with the nitrogen-fixing bacterium Pseudomonas protegens Pf-5 X940. Environmental Microbiology 2016, 18:3522-3534.

69. Drogue B, Sanguin H, Borland S, Prigent-Combaret C, Wisniewski-Dyé F: Genome wide profiling of Azospirillum lipoferum 4B gene expression during interaction with rice roots. FEMS Microbiology Ecology 2014, 87:543-555.

70. Drogue B, Sanguin H, Chamam A, Mozar M, Llauro C, Panaud O, PrigentCombaret C, Picault N, Wisniewski-Dyé F: Plant root transcriptome profiling reveals a strain-dependent response during Azospirillumrice cooperation. Frontiers in Plant Science 2014, 5.

71. Brusamarello-Santos LCC, Pacheco F, Aljanabi SMM, Monteiro RA, Cruz LM, Baura VA, Pedrosa FO, Souza EM, Wassem R: Differential gene expression of rice roots inoculated with the diazotroph Herbaspirillum seropedicae. Plant and Soil 2012, 356:113-125.

72. Giovannetti M, Mari A, Novero M, Bonfante P: Early Lotus japonicus root transcriptomic responses to symbiotic and pathogenic fungal exudates. Frontiers in Plant Science 2015, 6.

73. Hogslund N, Radutoiu S, Krusell L, Voroshilova V, Hannah MA, Goffard N, Sanchez DH, Lippold F, Ott T, Sato S, et al.: Dissection of Symbiosis and Organ Development by Integrated Transcriptome Analysis of Lotus japonicus Mutant and Wild-Type Plants. Plos One 2009, 4.

74. Donn S, Kirkegaard JA, Perera G, Richardson AE, Watt M: Evolution of bacterial communities in the wheat crop rhizosphere. Environmental Microbiology 2015, 17:610-621.

75. Mitter B, Petric A, Shin M, Chain P, Hauberg-Lotte L, Reinhold-Hurek B, Nowak J, Sessitsch A: Comparative genome analysis of Burkholderia phytofirmans PsJN reveals a wide spectrum of endophytic lifestyles based on interaction strategies with host plants. Frontiers in Plant Science 2013, 4.

**76. Panke-Buisse K, Poole AC, Goodrich JK, Ley RE, Kao-Kniffin J: Selection on soil microbiomes reveals reproducible impacts on plant function. ISME J 2015, 9:980-989.

This study demonstrates how a subset of the soil microbiome can be artificially manipulated using plant selection platform.

77. Panke-Buisse K, Lee S, Kao-Kniffin J: Cultivated Sub-Populations of Soil Microbiomes Retain Early Flowering Plant Trait. Microb Ecol 2016.

78. Fiegna F, Moreno-Letelier A, Bell T, Barraclough TG: Evolution of species interactions determines microbial community productivity in new environments. ISME J 2015, 9:1235-1245.

79. Bell TH, Stefani FO, Abram K, Champagne J, Yergeau E, Hijri M, St-Arnaud M: A Diverse Soil Microbiome Degrades More Crude Oil than 
Specialized Bacterial Assemblages Obtained in Culture. Appl Environ Microbiol 2016, 82:5530-5541.

80. van Elsas JD, Chiurazzi M, Mallon CA, Elhottova D, Kristufek V, Salles JF: Microbial diversity determines the invasion of soil by a bacterial pathogen. Proc Natl Acad Sci U S A 2012, 109:1159-1164.

81. Quinn RA, Navas-Molina JA, Hyde ER, Song SJ, Vázquez-Baeza Y, Humphrey G, Gaffney J, Minich JJ, Melnik AV, Herschend J, et al.: From Sample to Multi-Omics Conclusions in under 48 Hours. mSystems 2016, 1.

**82. Poudel R, Jumpponen A, Schlatter DC, Paulitz TC, Gardener BB, Kinkel LL, Garrett KA: Microbiome Networks: A Systems Framework for Identifying Candidate Microbial Assemblages for Disease Management. Phytopathology 2016, 106:1083-1096.

A well-explained network analysis approach. Networks based on correlation analysis allow for identifying of taxa actually inolved in plant yield or pathogen suppression. This study also underlies the importance of key species (microbial network hubs).

83. Yin C, Hulbert SH, Schroeder KL, Mavrodi O, Mavrodi D, Dhingra A, Schillinger WF, Paulitz TC: Role of bacterial communities in the natural suppression of Rhizoctonia solani bare patch disease of wheat (Triticum aestivum L.). Appl Environ Microbiol 2013, 79:74287438.

84. Bai Y, Müller DB, Srinivas G, Garrido-Oter R, Potthoff E, Rott M, Dombrowski N, Münch PC, Spaepen S, Remus-Emsermann M, et al.: Functional overlap of the Arabidopsis leaf and root microbiota. Nature 2015, 528:364-369.

Figure legends

Figure 1. A. Origin of the plant microbiome. The main origin of the plant microbiome is the soil, where the microbial diversity is inversily correlated with the activity of its community. In addition to the microorganisms that potentially migrate from the soil to the leaves, the phyllosphere is also colonised by specialised air-borne species. Another source in some plant species, is the seed-borne community that is inherited vertically. B. Microbial-plant dialogue. Microbes are attracted by root exudates, and their presence triggers a plant specific response. Chemical signalling and surface structures are perceived by LysM receptors in the plant membrane, which will then modulate microbial recognition.

Figure 2. Proposed synthetic inoculant based on keystone species. Keystone and diverstiy based approach expands the historical single or mixed inoculant approaches. 
Current Opinion mini-review

PGPR species will promote plant growth and pathogen protection direct or indirectly. Keystone species will then provide a support for the PGPRs either directly, with a help of just a few "middle" species (intermediate influence) or indirectly through a diverse, interconnected community. The arrows and the bar-heads at the end of the nodes indicate a positive and negative influence, respectively. 